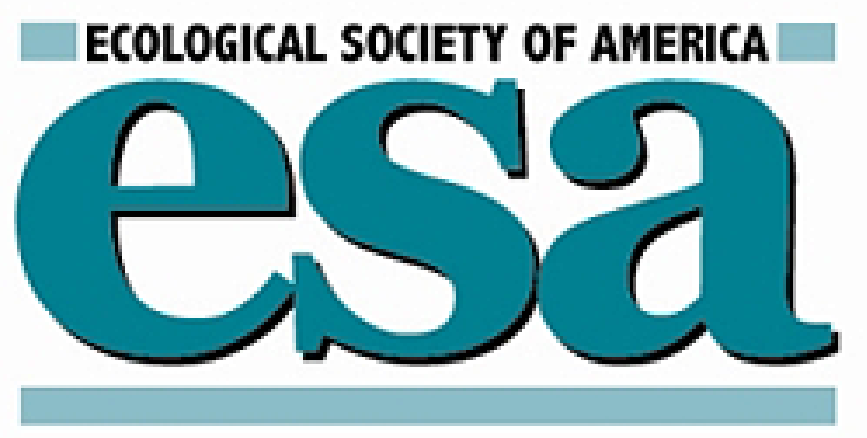

Spatial and Temporal Variation in Soil and Vegetation Impacts on Campsites Author(s): Jeffrey L. Marion and David N. Cole

Source: Ecological Applications, Vol. 6, No. 2 (May, 1996), pp. 520-530

Published by: Ecological Society of America

Stable URL: http://www.jstor.org/stable/2269388

Accessed: 12/03/2014 10:36

Your use of the JSTOR archive indicates your acceptance of the Terms \& Conditions of Use, available at http://www.jstor.org/page/info/about/policies/terms.jsp

JSTOR is a not-for-profit service that helps scholars, researchers, and students discover, use, and build upon a wide range of content in a trusted digital archive. We use information technology and tools to increase productivity and facilitate new forms of scholarship. For more information about JSTOR, please contact support@ jstor.org. 


\title{
SPATIAL AND TEMPORAL VARIATION IN SOIL AND VEGETATION IMPACTS ON CAMPSITES ${ }^{1}$
}

\author{
JEFFREY L. MARION \\ Cooperative Park Studies Unit, National Biological Service, U.S. Department of the Interior, \\ Virginia Polytechnic Institute and State University, Blacksburg, Virginia 24061-0324 USA \\ DAVID N. COLE \\ Aldo Leopold Wilderness Research Institute, Forest Service, U.S. Department of Agriculture, \\ P.O. Box 8089, Missoula, Montana 59807 USA
}

\begin{abstract}
We studied the impacts of camping on soil and vegetation at Delaware Water Gap National Recreation Area. We assessed the magnitude of impact on campsites that varied in amount of use and in topographic position. We also evaluated change over a 5yr period on long-established, recently opened, and recently closed campsites, as well as on plots subjected to experimental trampling. Campsite impacts were intense and spatially variable. Amount of use and topographic position explained some of this variation. Soil and vegetation conditions changed rapidly when campsites were initially opened to use and when they were closed to use. Changes were less pronounced on the long-established campsites that remained open to use. In the trampling experiments, impact varied greatly with trampling intensity and between vegetation types. An open-canopy grassland vegetation type was much more resistant to trampling than a forb-dominated forest vegetation type. Campsite impacts increased rapidly with initial disturbance, stabilized with ongoing disturbance, and-in contrast to what has been found in most other studies-decreased rapidly once disturbance was terminated. Implications of these results for campsite management strategies, such as use concentration or dispersal, and rotation or closure of campsites, are discussed.
\end{abstract}

Key words: campsite impact; campsite recovery; Delaware Water Gap National Recreation Area; experimental trampling; northeastern United States; recreation ecology; recreation impact management; recreation impacts; riparian forests; temporal variation.

\section{INTRODUCTION}

The impacts of camping on the vegetation and soil of natural areas can be locally severe. These impacts compromise the integrity of natural ecosystems and diminish the quality of recreational experiences (Hammitt and Cole 1987). Although some disturbance is inevitable with recreational use, the magnitude and extent of its impact at campsites are both spatially and temporally variable. Spatial variation is readily apparent even to the casual observer. At fine scales, magnitude of disturbance is typically negatively correlated with distance from the center of the campsite (Stohlgren and Parsons 1986). Differences at coarse spatial scales are also apparent; certain campsites are more severely impacted than others and the areal extent of these changes varies widely across landscapes (Cole and Marion 1988). Variation in campsite impact is a function of use levels and characteristics, and the resistance and resilience of sites (Cole 1987a).

Temporal variation in impact is less apparent, but can be pronounced. Campsite conditions change over time, in response to the changes that are inherent to all natural systems, changes in the frequency and mag-

\footnotetext{
${ }^{1}$ Manuscript received 11 July 1994; revised 25 April 1995; accepted 2 May 1995.
}

nitude of camping disturbance, and the time lag between disturbance and response.

Information about spatial and temporal variation of campsite impacts is critical to minimizing the effects of recreational use in natural areas. Managers can utilize this information to develop strategies for managing the intensity, distribution, and timing of use. Better information will allow more informed decisions about the effects of concentrating or dispersing use, about the durability of different sites, about the appropriateness of a rest-rotation scheme for campsites, and about the ability of disturbed sites to recover.

Most campsite impact studies have been conducted in the western United States, prompting some to question the applicability of results and their management implications in other regions. Moreover, the ability to draw general conclusions from these studies has been hampered by the limited perspective any individual research approach can provide (Cole 1987a). Our goal, in this study, was to utilize complementary research approaches to assess spatial and temporal variation in impact on primitive campsites in the eastern United States. Our specific objectives were to (1) describe the magnitude of soil and vegetation impact on campsites in Delaware Water Gap National Recreation Area, (2) investigate the extent to which spatial variation in impact can be explained by variation in amount of use 
and site characteristics, and (3) describe temporal variation in impact on campsites that were previously undisturbed, campsites that have been long established, long-established campsites that have been closed to use, and sites that were experimentally trampled.

Detailed studies of the effects of camping and trampling on vegetation and soil can also contribute to a more general understanding of disturbance processes. Camping and trampling are examples of chronic stresses that cause disturbances of high intensity but low areal extent (sensu Connell and Slatyer 1977). Conclusions about spatial and temporal patterns for this disturbance type might be generally applicable to other chronic, high-intensity, low-area disturbances.

\section{STUdy AREA}

Delaware Water Gap National Recreation Area, a unit of the National Park Service, encompasses $\approx 28000$ ha of northeastern Pennsylvania and adjacent New Jersey. The park, centered along $65 \mathrm{~km}$ of the Delaware River, is part of the National Wild and Scenic River System. Located just $100 \mathrm{~km}$ northwest of New York City, the park can be reached within a 2-h drive by nearly $30 \times 10^{6}$ people. Much of the park has been designated as backcountry, with management objectives that stress preservation of natural ecosystems.

Canoeing is among the most popular recreation activities in the park. Although day use is predominant, $\approx 35 \%$ of canoers stay overnight. Overnight use at backcountry campsites (primarily accessed by canoe) was estimated at 33000 camper nights in 1991, the same level of use that has occurred every year for the past decade. Since 1983, camping has been confined to designated areas. In 1988-1989, camping was further confined to individual campsites, identified through the placement of permanently anchored fire grates. Through this action the total number of designated campsites was reduced from 116 to 87 sites. Use intensities on these remaining campsites have undoubtedly increased as a consequence.

\section{STUDY METHODS}

We conducted three interrelated studies, combining mensurative, comparative mensurative, and manipulative experiments (sensu Hurlbert 1984). First, measures taken on long-established, currently used campsites were compared with measures on neighboring undisturbed sites to estimate amount of campsite impact. The campsites were stratified by amount of use and topographic location to determine how these factors influence spatial variation in amount of impact. Repeated measures over $5 \mathrm{yr}$ provided estimates of temporal variation. Second, change over time was assessed on recently opened and also on recently closed campsites to determine how individual sites responded to the initiation and cessation of camping. Third, experimental trampling treatments were applied to previously undisturbed sites to evaluate how impact varied with amount of use and vegetation type over time. These experiments allowed us to vary amount of use and site characteristics (vegetation type), while holding other variables constant.

\section{Long-established campsites}

Campsites were stratified according to both amount of use and topographic position. Although site-specific visitor counts were lacking, use levels were estimated by experienced rangers and from limited registration data. Only sites that were clearly high-use sites (used 40-70 nights/yr) or low-use sites (used 3-10 nights/ yr) were considered for inclusion in the study. For topographic position we defined lowland sites as those closest to the river that are flooded annually; upland sites were those located on higher terraces that are infrequently flooded. Using these stratifications, we selected the first 29 designated campsites that met our criteria. The final sample consisted of 10 high-use upland sites, 8 high-use lowland sites, 4 low-use upland sites, and 7 low-use lowland sites. Each sample site consisted of both the established campsite and an environmentally similar undisturbed control site in the vicinity.

We established a permanent point close to the center of each campsite. We measured the distances from this point to the first vegetation and to the limit of obvious disturbance, in 16 directions, delineating a central area completely devoid of vegetation (nonvegetated area) and the larger campsite area. We also measured the length of riverbank vegetation obviously disturbed by landing boats (shoreline disturbance).

Within the boundaries of the campsite area we censused all trees. Trees $<140 \mathrm{~cm}$ tall but at least $0.5 \mathrm{yr}$ old were counted as tree reproduction. Trees $>140 \mathrm{~cm}$ tall were classified and counted as either damaged by humans (e.g., nails, broken branches, trunk scars) or undamaged by humans. Felled trees (tree stumps) were also counted. We systematically located 15-20 quadrats, $1-\mathrm{m}^{2}$ each, along four permanent transects radiating from the campsite center point to the boundary. The azimuth of the first transect was selected at random; the other three were oriented perpendicular to each other. Within each quadrat we estimated percent total vegetation ground cover (excluding trees), and cover for each vascular plant species, mosses, and exposed mineral soil. Estimates were for the entire quadrat, in $10 \%$ coverage classes between 10 and $100 \%$ and to the closest percent if $<10 \%$. Nomenclature follows Gleason and Cronquist (1963).

Within each of the 15-20 quadrats, we also took one measurement of the thickness of surface organic horizons and used a pocket soil penetrometer (Model CL700A, Soiltest, Chicago, Illinois, USA) to take two readings of the penetration resistance of the uppermost $6 \mathrm{~mm}$ of mineral soil. We collected eight soil samples from each campsite with a Tube Density Soil Sampler with $7.6 \mathrm{~cm}$ diameter and $7.6 \mathrm{~cm}$ high tubes (Model 
CN-1025, Soiltest, Chicago, Illinois, USA) to estimate moisture content and stone-free bulk density. Four samples were taken from different sectors of the highly impacted central part of each campsite; four others were taken in peripheral parts.

Control sites were selected on the basis of their topographic, vegetative, and edaphic similarity to each surveyed campsite. Control plots were circular, with a radius of $3 \mathrm{~m}$. Their size was determined through species-area curves derived from field trials in several riparian vegetation types. We estimated percentage cover of ground vegetation, each vascular plant species, mosses, and exposed mineral soil for the entire $30-\mathrm{m}^{2}$ control, using the same coverage classes as on campsites. We took 20 systematically distributed measures of organic horizon thickness and soil penetration resistance, and four soil samples for determination of moisture content and bulk density. Finally, we counted tree reproduction in a circular plot with a radius of $4 \mathrm{~m}$.

In 1991, 19 of these campsites and their controls were remeasured; the other campsites evaluated in 1986 had been closed by park managers in 1988-1989. Our 1991 sample consisted of 8 high-use upland sites, 7 high-use lowland sites, 1 low-use upland site, and 3 low-use lowland sites. Center points and quadrats were precisely relocated. All measures taken in 1986 were repeated on the same sample units as in 1986. However, tree damage and tree reproduction were assessed within the boundaries of the campsite in 1991, rather than the original sample unit, i.e., the campsite boundaries that existed in 1986. Change in species composition on campsites was quantified by calculating floristic dissimilarity (FD), a modification of Sorensen's similarity index:

$$
\mathrm{FD}=0.5 \Sigma\left|p_{1}-p_{2}\right|,
$$

where $p_{1}$ is the relative cover of a given species on the campsite and $p_{2}$ is the relative cover of the same species on the control site.

The statistical significance of differences for each parameter between campsites and their environmentally paired control sites was assessed with paired $t$ tests $(\alpha=0.05)$. Temporal differences between campsites and between control sites from 1986 to 1991 were also evaluated with paired $t$ tests. Two-way analyses of variance $(\alpha=0.05)$ were used to assess the extent to which spatial variation in impact could be explained by differences in amount of use and campsite location. Several variables were log-transformed to reduce heteroscedasticity.

\section{Recently opened and recently closed campsites}

In 1986, for purposes of this study, managers closed three long-established campsites and opened three new campsites that had never been used before. The three new campsites were identified by signs along the river. Steel fire grates were installed at each site and access trails were cleared. Initial measurements were taken in
June 1986 , prior to any campsite use, and repeated in June and September of 1986, 1987, and 1988, only in September in 1989 and 1990, and only in July in 1991. Measurements for both campsites and undisturbed control sites were identical to those on long-established campsites. Data from onsite registration boxes indicated that these sites received moderate use $(\approx 10-28$ overnight visits and 5-10 lunch visits per year).

On the three closed campsites, signs and fire rings were removed and river access trails were disguised with woody debris and vegetation transplants. No restoration work was done on the campsite proper, however. Visitor compliance with closure was good, with only three known instances of illegal camping. Prior to closure, all three campsites received low use $(\approx 5-$ 10 overnight visits per year). Measurements were identical to those for recently opened sites and occurred at the same times. Due to the small sample size, tests of statistical significance were not conducted. We make no attempt to extend our results beyond those of these specific campsites.

\section{Trampling experiments}

Controlled trampling experiments were conducted in the two most abundant plant communities along the riparian corridor. The first type, located on lowlands that flood annually, was a grassland with an open canopy of Acer saccharum and A. saccharinum. Mean cover of the dominant graminoid, Phalaris arundinacea, was $98 \%$. Forb cover was $<20 \%$, with Polygonum persicaria and Impatiens spp. most abundant. The second type, located on uplands that flood less frequently, was an Acer saccharum-A. saccharinum forest with a dense ground cover of forbs. The most abundant ground cover species were Lysimachia ciliata and Zizia aurea. Graminoid cover was $<5 \%$, with Carex davisii most abundant.

Trampling treatments were assigned to each of six lanes, each $0.5 \mathrm{~m}$ wide and $3 \mathrm{~m}$ long. Two lanes served as controls while the others received $10,50,250$, or 1000 passes. A pass is a one-way walk at a natural gait down the lane. Tramplers wore tennis shoes and had body masses of 55-65 kg. Trampling treatments were applied to two replicates of this experimental design during early August of 1986, 1987, and 1988. We assessed vegetation and soil response in three $30 \times 50$ $\mathrm{cm}$ subplots located along the center of each lane. In each subplot, we estimated the cover of each plant species and the cover of exposed mineral soil, using $10 \%$ coverage classes. We assessed soil compaction with five measures of penetration resistance taken below the unconsolidated surface organic litter horizon. During the $3 \mathrm{yr}$ of trampling, measurements were taken in $\mathrm{Au}-$ gust, immediately before and after trampling. Recovery from trampling disturbance was assessed with measurements in September of 1989 and 1990.

From these measures we derived three response indices: relative vegetation cover (RVC), increase in pen- 
TABLE 1. Vegetation and soil conditions on 29 campsites and undisturbed control sites at Delaware Water Gap National Recreation Area, 1986.

\begin{tabular}{|c|c|c|c|c|c|}
\hline \multirow[b]{2}{*}{ Impact parameter } & \multicolumn{2}{|c|}{ Campsite } & \multicolumn{2}{|c|}{ Control } & \multirow[b]{2}{*}{$P$} \\
\hline & Mean & Range & Mean & Range & \\
\hline Ground vegetation cover $(\%)$ & 15 & $0-63$ & 72 & $1-95$ & .001 \\
\hline Floristic dissimilarity (\%) & 75 & $23-100$ & \multicolumn{2}{|c|}{ n.a. $\dagger$} & \\
\hline Graminoid cover $(\%)$ & 58 & $0-100$ & 26 & $0-92$ & .023 \\
\hline Forb cover $(\%)$ & 23 & $0-78$ & 59 & $5-100$ & .001 \\
\hline Mineral soil cover $(\%)$ & 61 & $21-94$ & 1 & $0-15$ & .001 \\
\hline Organic horizon thickness $(\mathrm{cm})$ & 0.5 & $0-1.4$ & 1.5 & $0.2-3.1$ & .002 \\
\hline Soil bulk density $\left(\mathrm{g} / \mathrm{cm}^{3}\right)$ & 1.26 & $1.0-1.4$ & 1.06 & $0.7-1.4$ & .001 \\
\hline Soil penetration resistance $(\mathrm{kPa}) \neq$ & 275 & $137-382$ & 49 & $0-226$ & .001 \\
\hline Soil moisture $\left(\mathrm{g} / \mathrm{cm}^{3}\right)$ & 18 & $8-32$ & 17 & $8-31$ & .710 \\
\hline Felled trees $(\%)$ & 19 & $0-53$ & \multicolumn{2}{|c|}{ n.a. } & \\
\hline Damaged trees $(\%)$ & 77 & $25-100$ & & & \\
\hline Tree reproduction (stems/ha) & 936 & $0-6275$ & 10090 & $0-56400$ & .001 \\
\hline Nonvegetated area $\left(\mathrm{m}^{2}\right)$ & 181 & $0-696$ & 0 & $0-15$ & .001 \\
\hline Campsite area $\left(\mathrm{m}^{2}\right)$ & 269 & $51-731$ & & & \\
\hline Shoreline disturbance $(\mathrm{m})$ & 9 & $0-20$ & & & \\
\hline
\end{tabular}

$\dagger$ n.a. $=$ not applicable.

$\$ 1 \mathrm{kPa}=$ the pressure corresponding to $1.01971 \times 10^{-2} \mathrm{~kg} / \mathrm{cm}^{2}$.

etration resistance (IPR), and floristic dissimilarity (FD). Relative vegetation cover is a comparison of initial conditions (pre-trampling in 1986) and post-treatment conditions, with a correction factor (cf) applied to account for changes on control plots:

$$
\mathrm{RVC}=\frac{\begin{array}{c}
\text { surviving cover on } \\
\text { trampled subplots }
\end{array}}{\begin{array}{c}
\text { initial cover on } \\
\text { trampled subplots }
\end{array}} \times 100 \%
$$

where

$$
\mathrm{cf}=\frac{\text { initial cover on control subplots }}{\text { surviving cover on control subplots }} \text {. }
$$

Vegetation cover is based on the sum of the coverages of individual species, rather than a single estimate of vegetation cover.

Pre- and post-treatment penetration resistance (PR) measures were not compared because they responded greatly to short-term changes in soil moisture. Instead, change was inferred by comparing trampling lanes to controls as follows:

$$
\begin{aligned}
\mathrm{IPR}= & \text { PR on trampled subplots } \\
& -\mathrm{PR} \text { on control subplots. }
\end{aligned}
$$

The index of floristic dissimilarity provides a comparison of pre- and post-treatment species composition. The formula is identical to that used to compare campsites and control sites.

Analyses of variance $(\alpha=0.05)$ were used to assess the extent to which impacts varied with trampling intensity and between vegetation types.

\section{RESULTS}

\section{Camping impacts on vegetation and soils}

Soil and vegetation conditions on established campsites differed significantly from those on neighboring undisturbed control sites (paired $t$ tests; Table 1). The magnitude of these differences suggests that the impacts caused by camping were pronounced. They were also variable, as the wide ranges in condition in Table 1 illustrate. Most campsites had lost most of their ground vegetation cover and the high values for the floristic dissimilarity between campsites and control sites suggest that species composition was altered greatly by camping. Dissimilarity values for comparisons among undisturbed controls were much lower (mean of $30 \%$ ) than for differences between individual campsites and their paired controls (mean of $75 \%$ ).

Much of the shift in composition is reflected in a shift in the relative importance of graminoids and forbs on campsites. On control sites, forb species comprised almost two-thirds of the ground cover. Less than onethird of the cover was graminoids. On campsites, however, graminoid cover exceeded forb cover; mosses were also more abundant than on controls. Cover values for shrubs and tree seedlings were negligible both on campsites and controls. Non-native species were only slightly more prevalent on campsites than on controls, constituting $24 \%$ of cover on campsites and $19 \%$ of cover on controls. Most control sites had no mineral soil exposure, but mean mineral soil cover was $73 \%$ on campsites. Where organic horizons remained on campsites, they were typically only one-third as thick as on controls. Mineral soils have been compacted by camping; both bulk density and penetration resistance were significantly greater on campsites than controls. Of the soil characteristics we measured, only soil moisture content did not differ significantly between campsites and controls.

The tree overstory on campsites had also been affected substantially (Table 1). On average, $19 \%$ of the trees on the campsite had been felled and $77 \%$ of the standing trees had been damaged (primarily branches 
TABLE 2. Two-way ANOVA results for the effect of amount of use and topographic position on intensity of campsite impact, Delaware Water Gap National Recreation Area, 1986. All interactions were nonsignificant.

\begin{tabular}{|c|c|c|c|c|c|c|}
\hline \multirow[b]{3}{*}{ Impact parameter } & \multicolumn{6}{|c|}{ Source of variation } \\
\hline & \multicolumn{3}{|c|}{ Amount of use } & \multicolumn{3}{|c|}{ Topographic position } \\
\hline & Low & High & $P$ & Lowland & Upland & $P$ \\
\hline Vegetation cover decrease $(\%) \dagger$ & 55 & 59 & .33 & 75 & 39 & .001 \\
\hline Floristic dissimilarity (\%) & 64 & 78 & .10 & 74 & 71 & .57 \\
\hline Mineral soil cover increase $(\%) \dagger$ & 54 & 63 & .10 & 70 & 49 & .01 \\
\hline Organic horizon decrease $(\mathrm{cm}) \dagger$ & 0.28 & 0.51 & .67 & 0.03 & 0.84 & .003 \\
\hline Soil bulk density increase $\left(\mathrm{g} / \mathrm{cm}^{3}\right) \dagger$ & 0.17 & 0.22 & .54 & 0.21 & 0.19 & .88 \\
\hline Penetration resistance increase $(\mathrm{kPa}) \neq$ & 177 & 255 & .13 & 196 & 206 & .71 \\
\hline Damaged trees (number) & 6 & 15 & .03 & 8 & 16 & .13 \\
\hline Damaged trees $(\%)$ & 71 & 81 & .48 & 80 & 74 & .33 \\
\hline Nonvegetated area $\left(\mathrm{m}^{2}\right)$ & 74 & 246 & .03 & 136 & 228 & .38 \\
\hline Campsite area $\left(\mathrm{m}^{2}\right)$ & 125 & 357 & .001 & 197 & 347 & .16 \\
\hline Shoreline disturbance $(\mathrm{m})$ & 2 & 11 & $<.001$ & 8 & 7 & .47 \\
\hline
\end{tabular}

$\dagger$ Increase/decrease expressed as difference between campsite and control.

$\ddagger 1 \mathrm{kPa}=$ the pressure corresponding to $1.01971 \times 10^{-2} \mathrm{~kg} / \mathrm{cm}^{2}$.
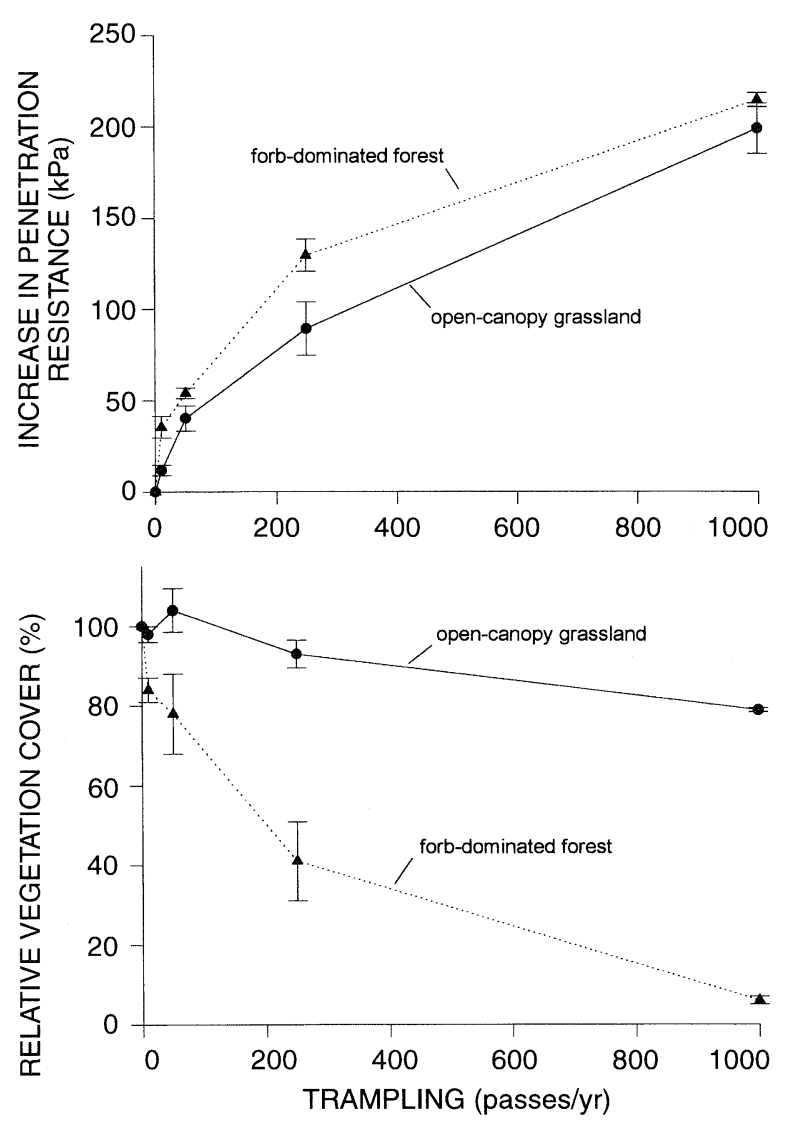

FIG. 1. Increase in soil penetration resistance and relative vegetation cover following three years of experimental trampling at 0-1000 passes/yr in an open-canopy grassland and a forb-dominated forest $(1 \mathrm{kPa}$ is the pressure corresponding to $\left.1.01971 \times 10^{-2} \mathrm{~kg} / \mathrm{cm}^{2}\right)$. Vertical bars are \pm 1 standard error. Increase in penetration resistance is the difference between conditions on trampled lanes and on paired controls. Relative vegetation cover is post-disturbance cover as a proportion of pre-disturbance cover, adjusted for changes on controls. cut for firewood or trunks scarred by axes and nails). The mean density of trees shorter than $140 \mathrm{~cm}$ on campsites (size classes considered indicative of tree reproduction) was only $9 \%$ of the density on control sites.

Finally, these impacts affected sizeable areas. The mean area entirely devoid of vegetation was $181 \mathrm{~m}^{2}$, while the mean contiguous area of camping disturbance was $269 \mathrm{~m}^{2}$. On average, $9 \mathrm{~m}$ of shoreline was disturbed by boat landings. Again, variation among sites was substantial. The largest campsite was $>14$ times as large as the smallest site.

\section{Spatial variation in impact}

Much of the spatial variation in impact can be explained by differences in amount of use and topographic location (Table 2). The amount of use a campsite received had a greater influence on the areal extent of impact than on the intensity of impact per unit area. High-use sites were significantly larger than low-use sites, with a larger nonvegetated area, more extensive shoreline disturbance, and more damaged trees on the campsite. However, none of the impacts that were assessed on a per-unit-area or percentage basis differed significantly between high- and low-use sites (Table 2).

There is clearly a positive relationship between use and impact. Differences between campsites and controls were substantial and impacts on high-use sites were generally more extensive, particularly for areal measures, than those on low-use sites. However, as has been reported in a number of previous studies of campsite impact (Cole 1987a), differences in impact were not linearly proportional to differences in amount of use. High-use sites were typically camped on $\approx 5-10$ times more often than low-use sites, while mean campsite area and nonvegetated area were only 2.9 and 3.3 times greater, respectively, on high-use sites than on low-use sites. For all types of impact that we measured, low-use sites were more similar to high-use sites than to control sites (Tables 1 and 2). 
This positive but nonlinear relationship between use and impact is even more evident in the results of the trampling experiments (Fig. 1). In both vegetation types, the increase in soil penetration resistance caused by trampling increased with trampling intensity; however, the rate of increase declined as trampling intensity increased. The rate of increase in vegetation loss also declined as trampling intensity increased in the forbdominated forest.

The intensity of impact on ground cover characteristics (assessed as the difference between campsites and controls) differed significantly between topographic positions (Table 2). Lowland campsites had lost more ground vegetation cover than had upland sites. They also had more mineral soil exposure, although they had lost less of their organic horizons. None of the measures of areal extent of impact varied significantly with topographic location, nor did any of the measures of intensity of change in mineral soil characteristics or tree damage. These results suggest that there is relatively little difference in durability between these locations.

Amount of impact varied more dramatically with site characteristics in the trampling experiments. In these experiments, sites were categorized by vegetation type rather than by topographic location (although the two are correlated). Vegetation loss differed significantly between vegetation types at trampling intensities $>50$ passes/yr (Fig. 1). Just 50 trampling passes/yr in the forb-dominated forest caused more vegetation loss than 1000 passes/yr in the open-canopy grassland. Differences between vegetation types in the magnitude of increase in penetration resistance were less substantial and not statistically significant (ANOVA, $P=0.056$ ). The more dramatic differences in impact in the trampling experiments suggest that (1) vegetation type may be a better predictor of amount of impact than topographic location and/or (2) that site characteristics are better predictors of impact when the disturbance regime is a short-term, low-intensity type (as simulated by the trampling experiments) rather than a long-term, highintensity type (as was the case on long-established campsites).

\section{Temporal variation}

Temporal variation in impact was not as pronounced as spatial variation on long-established campsites; however, rapid change in conditions occurred on both recently opened and recently closed campsites. Despite higher use levels on individual campsites in 1991 than in 1986 (overall use levels were constant but the number of designated sites was reduced) and a greater proportion of high-use sites in our 1991 sample, there is little evidence that campsite conditions deteriorated. The only statistically significant differences on longestablished campsites, between 1986 and 1991, were in tree damage and campsite area (Table 3). Mean campsite area declined 30\% between 1986 and 1991. The apparent increase in tree damage may be an artifact
TABLE 3. Change in mean vegetation and soil conditions on 19 campsites and undisturbed control sites at Delaware Water Gap National Recreation Area, 1986 to 1991.

\begin{tabular}{|c|c|c|c|}
\hline Impact parameter & 1986 & 1991 & $P$ \\
\hline \multicolumn{4}{|l|}{ Ground cover vegetation (\%) } \\
\hline $\begin{array}{l}\text { campsite } \\
\text { control site }\end{array}$ & $\begin{array}{l}15 \\
76\end{array}$ & $\begin{array}{l}22 \\
77\end{array}$ & $\begin{array}{l}.10 \\
.78\end{array}$ \\
\hline Floristic dissimilarity (\%) & 75 & 69 & .32 \\
\hline $\begin{array}{l}\text { Mineral soil cover }(\%) \\
\text { campsite } \\
\text { control site }\end{array}$ & $\begin{array}{r}65 \\
2\end{array}$ & $\begin{array}{r}56 \\
0\end{array}$ & $\begin{array}{l}.12 \\
.16\end{array}$ \\
\hline $\begin{array}{l}\text { Soil bulk density }\left(\mathrm{g} / \mathrm{cm}^{3}\right) \\
\text { campsite } \\
\text { control site }\end{array}$ & $\begin{array}{l}1.28 \\
1.05\end{array}$ & $\begin{array}{l}1.24 \\
0.96\end{array}$ & $\begin{array}{l}.28 \\
.06\end{array}$ \\
\hline $\begin{array}{l}\text { Soil penetration resistance } \\
\text { campsite } \\
\text { control site }\end{array}$ & $\begin{array}{r}304 \\
39\end{array}$ & $\begin{array}{r}275 \\
59\end{array}$ & $\begin{array}{l}.48 \\
.03\end{array}$ \\
\hline Damaged trees $(\%)$ & 84 & 98 & .002 \\
\hline $\begin{array}{l}\text { Tree reproduction }(\mathrm{stems} / \mathrm{h} \\
\text { campsite } \\
\text { control site }\end{array}$ & $\begin{array}{r}621 \\
11747\end{array}$ & $\begin{array}{r}262 \\
1505\end{array}$ & $\begin{array}{l}.19 \\
.01\end{array}$ \\
\hline Nonvegetated area $\left(\mathrm{m}^{2}\right)$ & 200 & 173 & .10 \\
\hline Campsite area $\left(\mathrm{m}^{2}\right)$ & 311 & 216 & .02 \\
\hline Shoreline disturbance (m) & 9 & 12 & .24 \\
\hline
\end{tabular}

of this decrease in campsite area since tree damage was only assessed within site boundaries. In 1991, campsites were smaller and there were fewer total trees and fewer damaged trees on these smaller campsites, but a larger proportion of the trees were damaged.

Most of the impact that occurred over the $6 \mathrm{yr}$ following campsite opening occurred during the first year of use (Fig. 2). Amount of impact increased each year for at least $3 \mathrm{yr}$, with ground cover impacts approaching their maxima more rapidly than impacts to the soil and changes in species composition. Partial recovery occurred during seasons without much use, but the magnitude of seasonal recovery declined with each successive year of use. Similar results have been reported elsewhere. Cole and Hall (1982) found little change on long-established campsites in the western United States and Merriam and Smith (1974) found that most impact to new campsites in northern Minnesota occurred in the first 2 yr after they were opened.

In the trampling experiments, maximum levels of vegetation loss occurred after the 1 st yr of trampling and maximum levels of penetration resistance occurred after the 2 nd yr of trampling. Fig. 3 shows the response of the forb-dominated forest; the open-canopy grassland responded in a similar manner. Substantial seasonal recovery occurred during the periods between trampling treatments (data not shown). In both vegetation types, seasonal recovery declined moderately with successive years of trampling, but not to the extent it declined on recently opened campsites. In western Montana, Cole (1987b) also found that near-maximum 

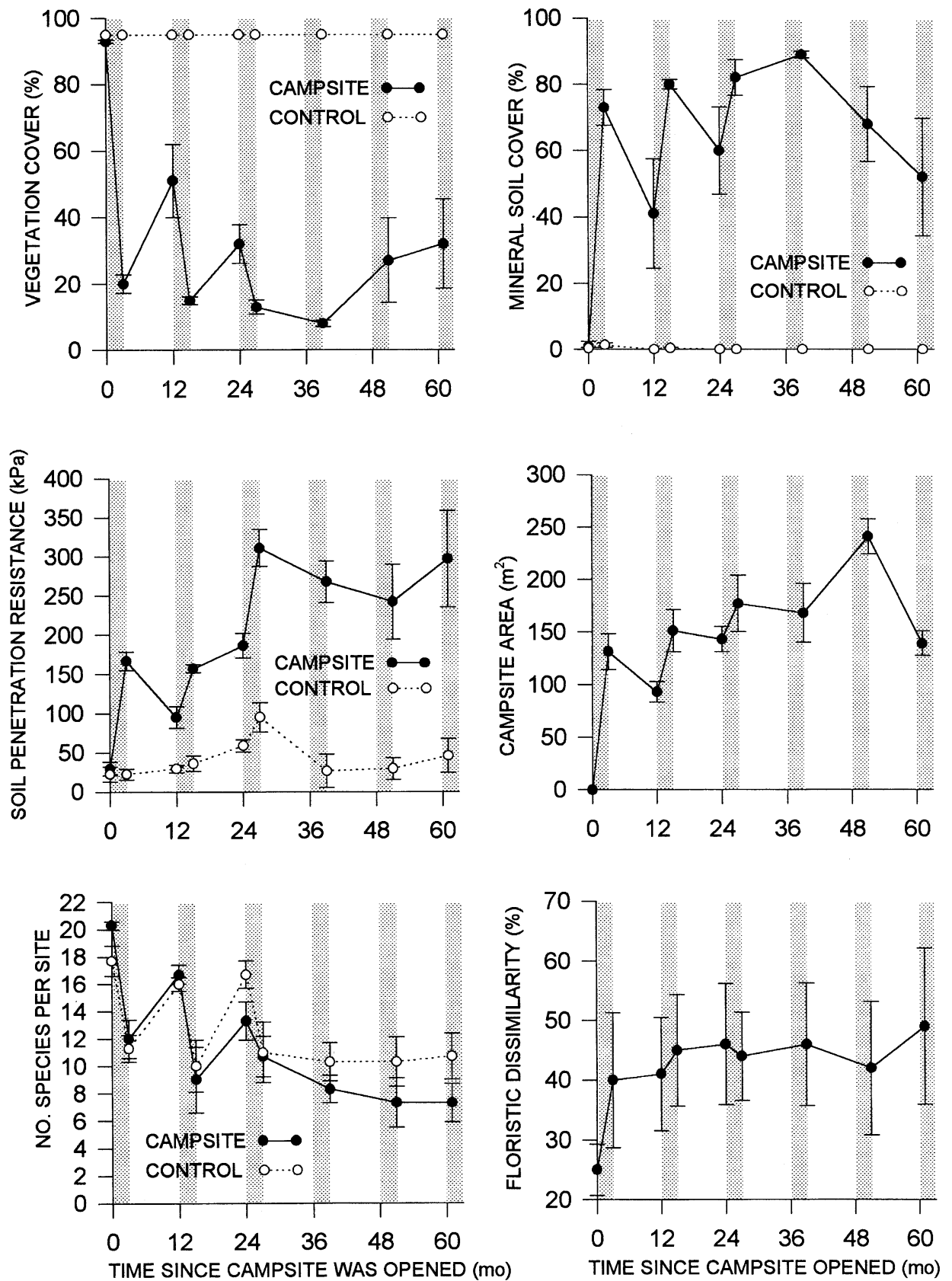

FIG. 2. Conditions on recently opened campsites (solid lines) and associated controls (dashed lines) during their initial $6 \mathrm{yr}$ of use. Vertical bars are \pm 1 standard error. Shaded areas denote the 3-mo season of heavy campsite use.

levels of impact occurred within the first $1-3 \mathrm{yr}$ of trampling and that seasonal recovery declined with each successive year of trampling.

Once camping disturbance was curtailed, site conditions changed rapidly. Most visual evidence of the campsite was absent within 6 yr of closure (Fig. 4). However, initial recovery rates on newly closed campsites were not as great as the initial deterioration rates on newly opened campsites (Figs. 2 and 5).

For most impact parameters, conditions on closed campsites were similar to those of undisturbed sites after just 2 yr without use (Fig. 5). However, both the density of tree reproduction and the floristic composition of the vegetation differed from undisturbed conditions even after $6 \mathrm{yr}$ of closure. This rate of recovery exceeded that reported for campsites in natural areas located at higher elevations (Cole and Ranz 1983, Stohlgren and Parsons 1986), including sites where recovery was assisted with transplants and soil amendments (Fay 1975, Moritsch and Muir 1993). These un- 
FIG. 3. Relative vegetation cover and increase in soil penetration resistance in a forbdominated forest following each of three years of experimental trampling at $0-1000$ passes/yr (solid lines, 1986-1988) and following two years without trampling (dashed lines, 19891990).
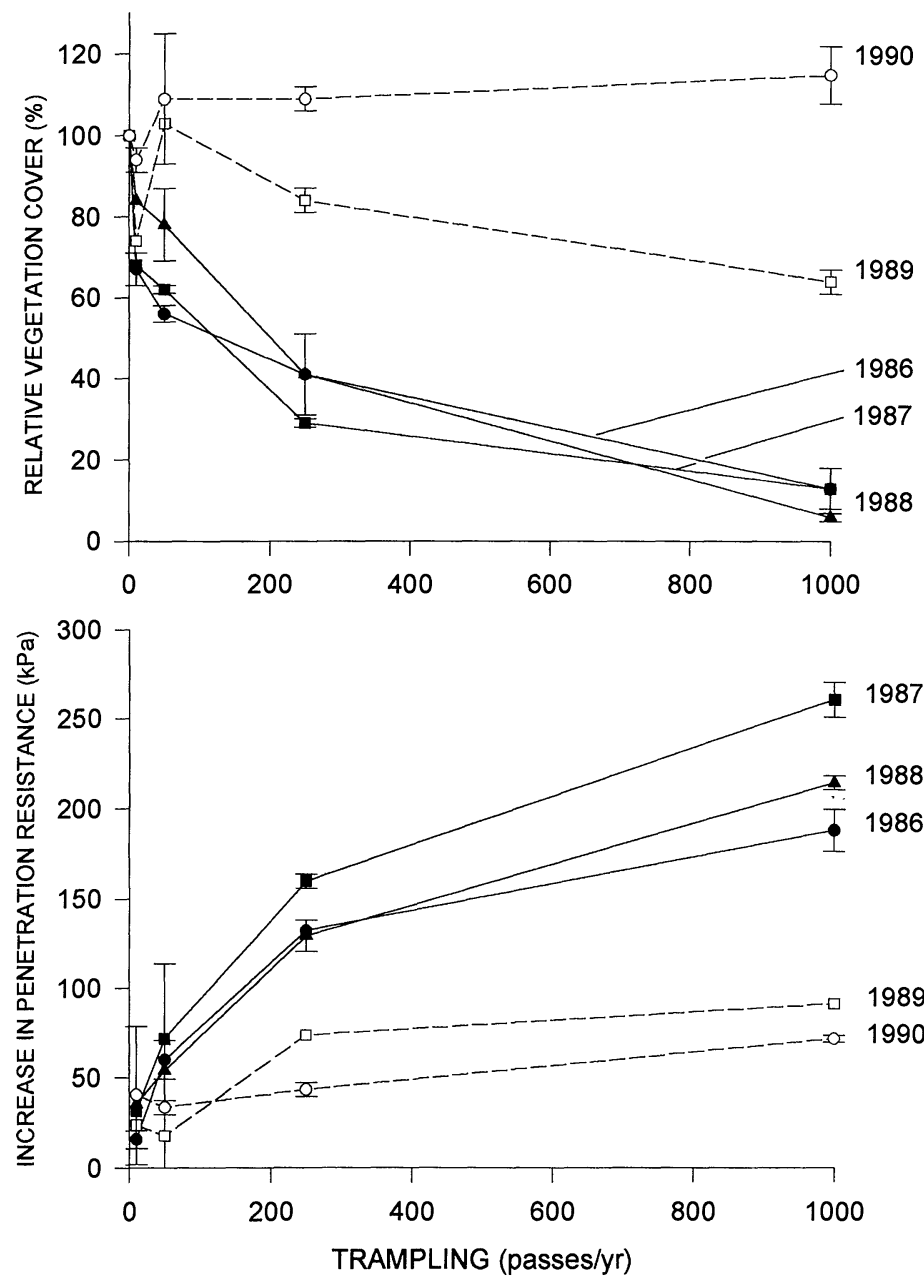

usually rapid recovery rates at Delaware Water Gap probably reflect the long growing season and fertile soils of these frequently flooded, low-elevation sites.

The magnitude of both within-year and between-year variation in condition of the recently closed established campsites was relatively constant, recovery being a steady but slow process. In contrast to the recently opened campsites, there were no seasonal reversals in trend because there was no alternation of disturbance and recovery. There also was no evidence of either a delay in recovery following closure or an initial period of pronounced recovery. In the trampling experiments, recovery was also rapid after trampling was curtailed (Fig. 3). Levels of vegetation cover were not significantly different from pre-disturbance levels after $2 \mathrm{yr}$ without trampling in the forest vegetation type (Fig. 3) and after $1 \mathrm{yr}$ in the open-canopy grassland type. In the grassland, none of the soil penetration resistance readings on trampled lanes exceeded those on controls after $1 \mathrm{yr}$ without trampling (data not shown). In the forb-dominated forest, however, readings on lanes trampled $>50$ times were significantly greater than those on controls $2 \mathrm{yr}$ after the final trampling treat- ment. Moreover, 2 yr after trampling was curtailed, vegetation species composition remained different from pre-disturbance conditions on the 250 - and 1000pass lanes (data not shown). Relative cover of graminoids and low-growing forbs remained higher than in pre-disturbance conditions, while relative cover of erect forbs remained lower.

\section{DISCUSSION}

The general conclusions of this study are that in the eastern deciduous forest environment characterizing Delaware Water Gap National Recreation Area: (1) camping impacts are intense but spatially variable; (2) the relationship between amount of use and amount of impact is positive but nonlinear; (3) conditions on longestablished sites are relatively stable; and (4) sites deteriorate more rapidly than they recover. We also found that the resistance of soil and vegetation subjected to camping and trampling was low. Pronounced change occurred rapidly even at low use intensities. Resilience was initially high, but it declined with time since the initiation of disturbance. Results from the different research approaches corroborated each other and results 

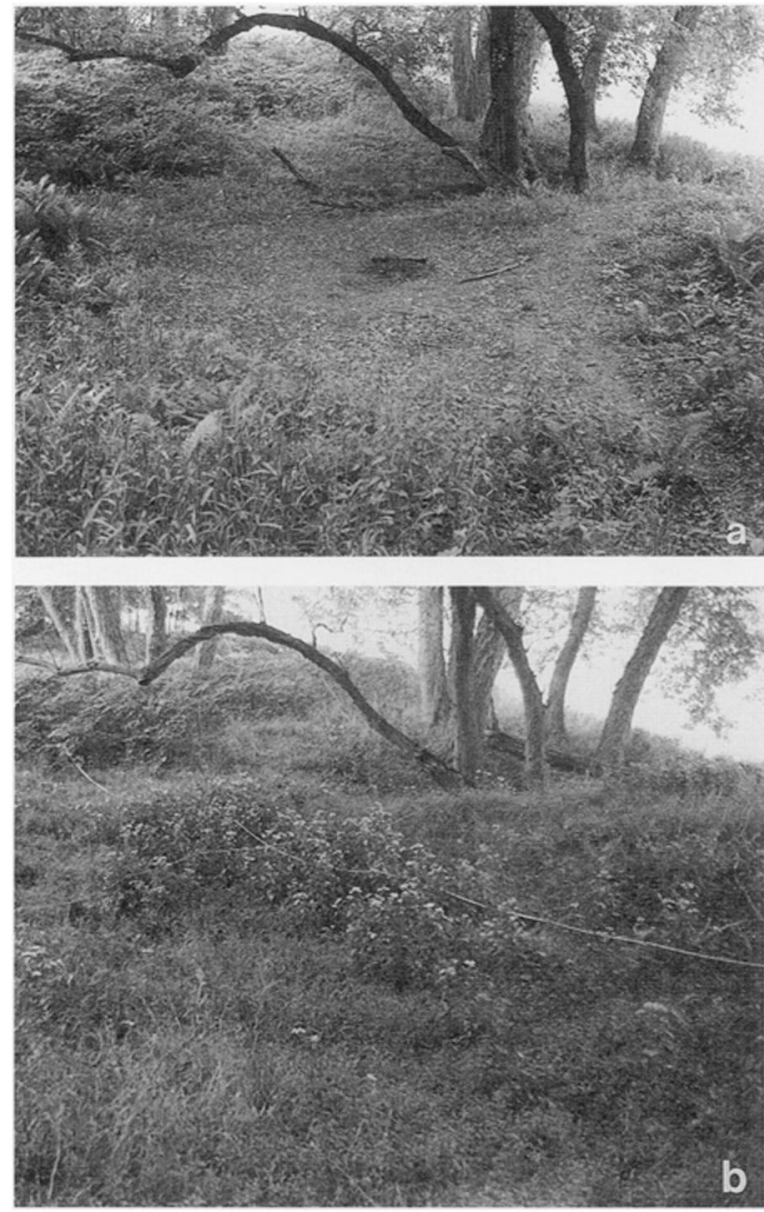

FIG. 4. Conditions on one campsite closed to use in 1986 (a) with substantial vegetative recovery by 1990 (b). Measuring tapes used for transects and establishment of vegetative quadrats are visible, crossed, in photograph (b).

from this natural area in the eastern United States were generally similar to those found in natural areas in the western United States. The most distinctive characteristic of the sites at Delaware Water Gap was their high resilience. Characteristics that might account for this include relatively fertile soils, long growing seasons, and periodic flooding.

Although generally low, the impact resistance of campsites at Delaware Water Gap was variable. Vegetation type appears to be a better predictor of vegetation durability than topographic position. Sites located under an open forest canopy and dominated by graminoids were highly resistant, while those located under a closed canopy and dominated by forbs were less resistant. This corroborates earlier studies which, almost without exception, have found vegetation types dominated by graminoids to be more resistant to trampling than those dominated by forbs (Cole 1995). It suggests that one effective management strategy might be locating campsites on durable sites, using vegetation type as a predictor of durability.
The results of these studies offer insights into the likely effectiveness of two other strategies for limiting campsite impact: concentrating use and rotating use among campsites. There has been considerable debate about whether it is better to concentrate or disperse recreation use in natural areas (Hendee et al. 1990). Some have argued that impact problems are a result of use being too highly concentrated in relatively few places (Echelberger et al. 1983). They argue that it would be better to attempt to disperse use more widely to achieve a more uniform distribution. Others have argued that impacts can be reduced by confining use to as few sites as possible, i.e., that dispersal of use only increases the areal extent of problems (Cole 1981).

Total campsite impact is the product of both the number of campsites and the intensity of impact on individual sites. Dispersing use will increase the number of campsites and decrease the intensity of impact on individual sites; concentrating use will have the opposite effect. The relationship between the dispersion of camping and the number of campsites should be positive and approximately linear. As we found at Delaware Water Gap, however, the relationship between amount of use and intensity of impact is positive and curvilinear. This suggests that total campsite impact should usually be less on a small number of high-use campsites than on a large number of low-use campsites. The most effective means of minimizing total impact, at least in our study environment, is to maximize the spatial concentration of use and impact.

Midway through our study, managers at Delaware Water Gap undertook actions that served to increase the concentration of use at two spatial scales. They increased the intersite concentration of use by reducing the number of designated campsites $25 \%$, i.e., from 116 to 87 sites. They also increased the intrasite concentration of use by installing fire grates on each site. This centralized activities more than in previous years, when visitors built fires on many different parts of the site. Consequently, mean campsite area declined $>30 \%$ between 1986 and 1991. The effect of these combined actions was a 50\% reduction in the total area of campsite disturbance-from 2.8 ha in 1986 to 1.4 ha in 1991 . Although these management actions increased the intensity of use on and within individual campsites, our findings suggest that there was no resultant increase in the intensity of impact on individual campsites (Table 3).

A campsite management strategy that is most frequently employed in developed recreation areas is to temporarily close highly impacted sites, allowing them to recover before they are opened to use again (Legg et al. 1980). In most backcountry areas this rest-rotation management strategy has been found ineffectual because recovery rates are so slow (Cole and Ranz 1983). At Delaware Water Gap, however, relatively rapid recovery rates on both closed campsites and experimental trampling plots suggest that this strategy might 

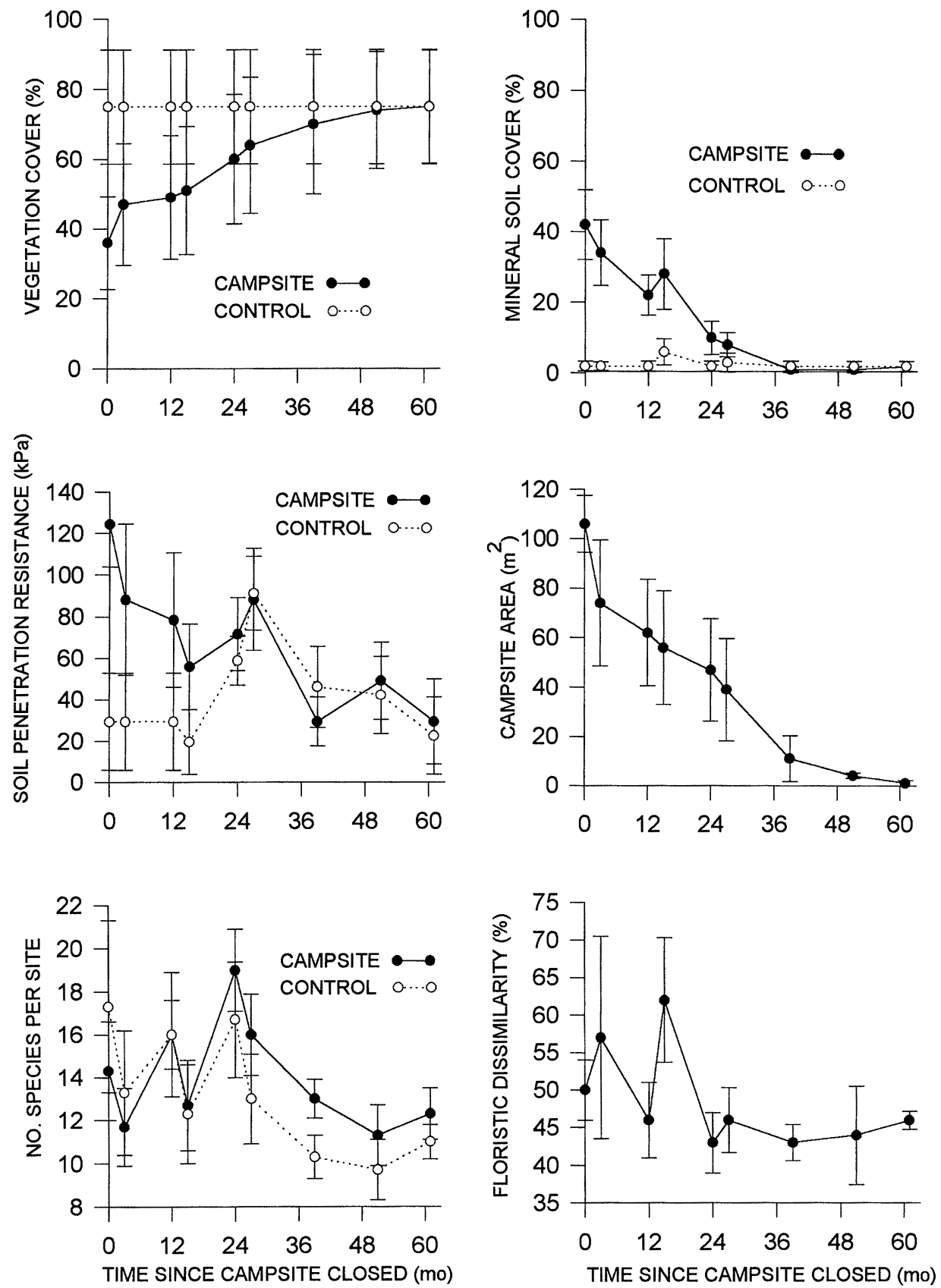

FIG. 5. Conditions on recently closed campsites (solid lines) and associated controls (dashed lines) during their initial 6 yr of closure. Vertical bars are \pm 1 standard error.

be an effective means of controlling impacts. Even here, however, such a strategy should be undertaken with caution. Our studies of recovery rates were confined to low-use campsites and small experimental plots that were only disturbed on $1 \mathrm{~d}$ for each of three successive years. Moreover, although vegetation cover rapidly returned to pre-disturbance levels, species composition remained divergent from pre-disturbance conditions 6 yr after closure.

In attempting to predict successional processes, Con- nell and Slatyer (1977) found it useful to distinguish between disturbance types in terms of their intensity and areal extent. This distinction may also be useful in predicting spatial and temporal patterns of response to disturbance and in selecting appropriate management strategies. For camping and trampling disturbance, we found asymptotic relationships both between impact intensity and time since disturbance was initiated, and between impact intensity and frequency of disturbance. Near-maximum impact intensities were produced very 
rapidly at any location that was repeatedly disturbed. We hypothesize that such relationships may be the norm for chronic disturbances of high intensity and low areal extent. Given this disturbance regime, magnitude of disturbance is determined more by variation in areal extent of impact than variation in intensity of impact. Consequently, management actions that concentrate the disturbing agent are likely to be most effective in minimizing impact levels.

\section{ACKNOWLEDGMENTS}

Financial support for this study was provided by the U. S. Department of the Interior National Park Service, Mid-Atlantic Regional Office. We appreciate the administrative and logistical assistance provided by John Karish and Beth Johnson.

\section{LiterATURE Cited}

Cole, D. N. 1981. Managing ecological impacts at wilderness campsites: an evaluation of techniques. Journal of Forestry 79:86-89.

2. 1987a. Research on soil and vegetation in wilderness: a state-of-knowledge review. Pages 135-177 in R. C. Lucas, compiler. Proceedings-national wilderness research conference: issues, state-of-knowledge, future directions. U.S. Forest Service General Technical Report INT-220, Intermountain Research Station, Ogden, Utah, USA.

1987b. Effects of three seasons of experimental trampling on five montane forest communities and a grassland in western Montana, USA. Biological Conservation 40:219-244.

1995. Experimental trampling of vegetation. II. Predictors of resistance and resilience. Journal of Applied Ecology 32:215-224.

Cole, D. N., and T. E. Hall. 1992. Trends in campsite condition: Eagle Cap Wilderness, Bob Marshall Wilderness, and Grand Canyon National Park. U.S. Forest Service Re- search Paper INT-45, Intermountain Research Station, Ogden, Utah, USA

Cole, D. N., and J. L. Marion. 1988. Recreation impacts in some riparian forests of the Eastern United States. Environmental Management 12:99-107.

Cole, D. N., and B. Ranz. 1983. Temporary campsite closures in the Selway-Bitterroot Wilderness. Journal of Forestry 81:729-732.

Connell, J. H., and R. O. Slatyer. 1977. Mechanisms of succession in natural communities and their role in community stability and organization. American Naturalist 111:11191144.

Echelberger, H. E., R. E. Leonard, and S. P. Adler. 1983. Designated-dispersed tentsites. Journal of Forestry 81:90$91,105$.

Fay, S. 1975. Ground-cover vegetation management at backcountry recreation sites. U. S. Forest Service Research Note NE-201, Northeastern Forest Experiment Station, Broomall, Pennsylvania, USA.

Gleason, H. A., and A. Cronquist. 1963. Manual of vascular plants of northeastern United States and adjacent Canada. Van Nostrand, Princeton, New Jersey, USA.

Hammitt, W. E., and D. N. Cole. 1987. Wildland recreation ecology and management. John Wiley and Sons, New York, New York, USA.

Hendee, J. C., G. H. Stankey, and R. C. Lucas. 1990. Wilderness management. North American Press, Golden, Colorado, USA.

Hurlbert, S. H. 1984. Pseudoreplication and the design of ecological field experiments. Ecological Monographs 54: 187-211.

Legg, M., K. Farnham, and E. Miller. 1980. Soil restoration on deteriorated campsites in Texas. Southern Journal of Applied Forestry 4:189-193.

Merriam, L. C., and C. K. Smith. 1974. Visitor impact on newly developed campsites in the Boundary Waters Canoe Area. Journal of Forestry 72:627-630.

Moritsch, B. J., and P. S. Muir. 1993. Subalpine revegetation in Yosemite National Park, California: changes in vegetation after three years. Natural Areas Journal 13:155-163.

Stohlgren, T. J., and D. J. Parsons. 1986. Vegetation and soil recovery in wilderness campsites closed to visitor use. Environmental Management 10:375-380. 